\title{
Study on the Efficiency of SMEs' Bank Financing in Clusters
}

\author{
Ke Liu, Lan Wang \\ School of International Business, Beijing Language and Culture University, Beijing, China.
}

Received 2013

\begin{abstract}
The critical factor in business strategic development process is financial resources. In this paper, we develop a model that examines how small and family firms got financial resources from the bank and explore how different levels of relationship affect the efficiency of bank financing. Based on literature review and field study, the research reveals that the inter-person relationship and inter-firm relationship facilitate the reputation of firm and then promote the bank financing performance. Further, practical suggestions are discuss for small and media firm in clusters.
\end{abstract}

Keywords: Bank Financing; Strategic Development Management; Clusters

\section{Introduction}

As the rapid development of industrial clusters in recent years, the financing of SMEs in industrial clusters has been given more concern. In the age of economic globalization, the industrial cluster, as an international form of the industrial layout, integrate into global supply chains, share the industrial division of economic globalization and form competitive industry, further enhancing the international competitiveness. Financing is a critical bottleneck problem in the development of SMEs. SMEs' business activities are more closely embedded in the network because of its geographical location closeness[1], promoting the exchange of information and the dissemination of knowledge.

\section{Literature Review and Hypothesis}

In the growth and expansion process, businesses often encounter the financial constraints in order to maintain and enhance the competitive advantage. Effective obtains of external financing for SMEs are particularly difficult. One crucial reason is that the market environment of SMEs is dispersed, which lack adequate asset and the scale capability is weak. Besides, they lack relevant information and knowledge of management and operation so that banks and other financial institutions find difficult to provide high quality financial services to SMEs[2].

Past researches of external financing problems of SMEs are mainly based on asymmetric information and agency theory. Some studies believe that the full understanding and disclosure of hard information (enterprise's assets, liabilities, profitability ratio, etc.) and soft infor- mation (the lending relationship with financial institutions) can reduce information asymmetries and agency costs[3], thereby enhancing the financing quality of enterprises; However, such theory does not fully reveal the special character of clusters, so this paper will try to analyze the financing process of industrial clusters from the perspective of the management theory.

In order to test different types of relationship's effect on the efficiency of bank financing, two categories (inter-person relationship and inter-firm relationship) were defined as factors promoting the bank financing performance and explore how the two kind of relationship could be used to effectively influence bank financing. First, we develop our theory and research hypotheses. We discuss how inter-person relationship and inter-firm relationship facilitate innovation performance. Next, we describe our methods to test these hypotheses. Finally, we present the results of the study and discuss their implications.

\subsection{Inter-person Relationship and Bank Financing}

Inter-person relationship plays a vital role in success of SMEs in many scenarios [4]. Inter-person relationship can be seen as a resources platform for managers, including financial, information, advice and emotional support and so forth. Inter-person relationship can help companies to get support and resources in the clusters like guarantee [5]. Specifically, the inter-person relationship promotes corporate image through friends and relatives, thereby let the banks more easily got the information. Besides, banks could have deep understanding 
of the firm though inter-person relationships [6]. It shows that a high level of inter-person relationship contributes to businesses' bank financing and played a role in the financing process. Therefore, we assume that:

H1 The higher the level of inter-person relationship, the higher the level of enterprise bank financing performance.

\subsection{Inter-firm Relationship and Bank Financing}

High level of inter-firm relationships means that they do not try to solve the problem in the process of damaging each other's interests [7]. They do not care gain or loss in the collaboration or have opportunistic behaviors. High level of inter-firm relationship shows good performance and partner history of the two sides and further improving the companies' financial efficiency from banks [8]. Actually, mutual trusted businesses will pay extra efforts to overcome difficulties and help each other to solve problems because they understand the situation of each other and have full information, so the good credit is more likely to occur [9]. The more stable the long-term oriented trade relationship between enterprises, the more opportunities of external financing, the more possibilities of enterprises' getting financial resources from the bank. Therefore, we assume that:

H2 The higher the level of inter-firm relationship, the higher the level of enterprise bank financing performance.

\section{Research Method}

\subsection{Sample and Data Collection}

This paper uses statistical tool to analyze the model and also based on through the literature review, expert consultation and semi-open questionnaires, etc. Before sending out the questionnaires, we will consult three experts about the description methods of questions and contents, adjusting the questionnaire mainly from theoretical viewpoint and long-term management and consulting experience. We elect several enterprises to do further evaluation and interviews, consulting senior executives and in-depth interviews, and form the final questionnaire used in this study.

On this basis, this research cooperates with Private Enterprises Business Association in Wenzhou, Zhejiang Province. We selected 700 companies randomly from the Association's Business Directory, sent out700 questionnaires from early October 2007 to the end of 2008, and collected 305 questionnaires back, reaching $43.5 \%$.In the returned questionnaires, there were 94 with incomplete content or obvious errors and be removed as invalid questionnaires. The 211 valid questionnaires were effective response, with a valid rate of $30.1 \%$. In order to ensure that data does not exist non-response bias, we do
Chi-square analysis to early and late recovery questionnaire in the enterprise's employee number and sales revenues. The result shows that the questionnaire in the two groups has no significant difference, indicating that the data was not significant non-response bias. Table $\mathbf{1}$ is the statistical analysis of sample firm business sales.

\subsection{Measurement}

This measurement uses the 5-point scale table. According to the actual situation and the degree of consistency from "totally disagree" to "completely agree", respondents give scores from 1 to 5 . In order to avoid the problems, this study Harman single-factor test. The method is to use all items in factor analysis, without rotation by getting the first principal component, which reflects the amount of CMV. In this article, all questionnaire items (independent variables and dependent variables) are used in factor analysis; five factors explained $56 \%$ of total variance. We find that the first factor explained only $26 \%$ of the variance, which indicates that no single factor could interpret most of the variance; therefore, the homology error of the research is not severe.

In addition, this study uses internal consistency method to test Cronbach's $\alpha$ reliability. The reliabilities of all variables are, inter-firm relationship $(\alpha=0.6)$, interperson relationship $(\alpha=0.5)$, bank financing efficiency $(\alpha=0.7)$. Therefore, the variables in this study have good reliability.

Table 1. Distribution of respondents.

\begin{tabular}{lcc}
\hline & $\mathrm{N}$ & $\%$ \\
\hline Sales revenues (in million RMB) & & \\
Less than 1 & 3 & 1.5 \\
$1-5$ & 6 & 3.1 \\
$5-10$ & 12 & 6.2 \\
$10-30$ & 38 & 19.6 \\
$30-100$ & 83 & 42.8 \\
Above 100 & 52 & 26.8 \\
Total & 211 & 100 \\
Total & 211 & 100 \\
\hline
\end{tabular}

Table 2. Correlation matrix and summary statist.

\begin{tabular}{lccc}
\hline \multicolumn{1}{c}{ Variables } & 1 & 2 & 3 \\
\hline 1. Inter- person relationship & 1 & & \\
2. Inter-firm relationship & $0.184^{*}$ & 1 & \\
3. Bank financing & $0.173^{*}$ & $0.228^{* *}$ & 1 \\
Mean & 3.798 & 3.207 & 2.946 \\
S.D. & .5570 & .4831 & .7885 \\
\hline
\end{tabular}

$* \mathrm{p}<0.05 ; * * \mathrm{p}<0.01 ; * * * \mathrm{p}<0.001$ (two-tailed test) 


\section{Test Results of the Model}

In this paper, we use two multi-regression models to test the proposed hypothesis.

Model 1 uses the bank financing efficiency as the dependent variable. In test hypothesis 1 , inter-person relationship has a positive significant effect on bank financing.

In regression model 1 , to test $\mathrm{H} 1$ the higher the level of inter-person relationship, the higher the level of enterprise bank financing performance. We put in control variable, independent variables (inter-person relationship) $(\beta=0.85, \mathrm{p}<0.01)$; when put into the social relationship variables, it increases significant level of the dependent variable's interpretation $(\Delta R 2=0.034)$ in $p<0.01$. Thus, the assumption 1 the higher the level of inter-person relationship, the higher the level of enterprise bank financing performance is supported is supported. Then we put in independent variables (inter-firm relationship) $(\beta=0.158$, $\mathrm{p}<0.05$ ); when put into the social relationship variables, it increases significant level of the dependent variable's interpretation $(\Delta \mathrm{R} 2=0.022)$ in $\mathrm{p}<0.05$. Thus, the assumption 2 the higher the level of inter-firm relationship, the higher the level of enterprise bank financing performance is supported.

Table 3. Results of regression analyses.

\begin{tabular}{|c|c|c|c|c|}
\hline \multirow[t]{2}{*}{ Variables } & \multicolumn{2}{|c|}{$\begin{array}{l}\text { Model } 1 \\
\text { The efficiency of bank } \\
\text { financing performance }\end{array}$} & \multicolumn{2}{|c|}{$\begin{array}{l}\text { Model } 2 \\
\text { The efficiency of bank } \\
\text { financing performance }\end{array}$} \\
\hline & $\begin{array}{c}\text { Step1 } \\
\text { controls }\end{array}$ & $\begin{array}{c}\text { Step2 } \\
\text { IV(main effect) }\end{array}$ & $\begin{array}{c}\text { Step1 } \\
\text { controls }\end{array}$ & $\begin{array}{c}\text { Step2 } \\
\text { IV (main effect) }\end{array}$ \\
\hline Industry & -.104 & -.100 & -.104 & -.095 \\
\hline business type & -.063 & -.059 & -.063 & -.080 \\
\hline firm size & .013 & .038 & .013 & .026 \\
\hline sale Revenues & .106 & .109 & .106 & .077 \\
\hline total asset & $.222 *$ & $.205^{*}$ & .222 & $.196 *$ \\
\hline IP & & $.185 * *$ & & \\
\hline IF & & & & $.158^{*}$ \\
\hline $\mathrm{R} 2$ & .103 & .137 & .103 & .126 \\
\hline Increase in R2 & - & $.034 * *$ & - & $.022 *$ \\
\hline F-value & 4.579 & $5.237 * * *$ & 4.579 & $4.741 * * *$ \\
\hline
\end{tabular}

$\dagger p<0.10 ; * p<0.05 ; * * p<0.01 ; * * * p<0.001$ (two-tailed test)

\section{Conclusion and Implication}

The purpose of this research is to explore different types of relationship - inter person and inter-firm relationship impact on corporate bank financing, which has a great significance for us to understand the path of SMEs' financing in industrial cluster. The result reveals that inter person relationship brings benefits to businesses' bank financing and inter firm relationship also plays a vital role in this process. i.e. the higher the level of inter-firm relationship, the higher the level of corporate bank financing performance.

The two issues explored in this research have a significant reference meaning to management practices. The value of relationship brought by inter-person and inter-firm relationship is significant. Long-term inter-firm relationship increases the opportunities of providing information. Managers should pay attention to enhance its reputation level in the network by building relationships[10].

\section{Limitations of the Research}

Although this study makes exploration in the field of the financing theory and the strategy management, there are still some shortcomings, First of all, because we only examined two types of enterprise relationships, even though these two elements are important, they cannot represent all characteristics of the relationship. Further research could consider integrating other variables into the model. Secondly, the paper does not classify different types external financing channels, thus future research could explore the difference.

\section{Acknowledgements}

This paper is sponsored by Beijing Language and Culture University "twelfth five-year plan" project(Project Number:11GH05 ) Research on the internationalization of $\mathrm{RMB}$

\section{REFERENCES}

[1] Y. Z. Sun and J. F. Wei. "Industrial Clusters Based on Information Space Constrain," Modern Economic Science, Vol. 31, No. 2, 2009, pp. 72-77.

[2] N. A. Berger and G. F. Udell, "Small Business Credit Availability and Relationship Lending: The Importance of Bank Organizational Structure," Economic Journal, Royal Economic Society, Vol. 112, No. 447, 2002, pp. F32-F53. doi:10.1111/1468-0297.00682

[3] M. E. Porter, "Clusters and the New Economics of Competition," Harvard Business Review, 1998, Vol. 76, Vol. 6, p. 77.

[4] D. Evans and L. Leighton, "Some Empirical Aspects of Entrepreneurship," American Economy Review, 1989, Vol. 
79, No. 3, pp. 519-535.

[5] H. Hoang and B. Antoncic, "Network-based Research in Entrepreneurship: A Critical Review," Journal of Business Venturing, Vol. 18, 2003, pp. 165-187. doi:10.1016/S0883-9026(02)00081-2

[6] C. H. Xu, "Reasons and Solutions of the Difficult of SMEs," Financing, Business Econonmy and Management, Vol. 2, 2007, pp. 64-67.

[7] F. Allen, J. Qian and M. Qian, "Law, Finance and Economic Growth in China," Journal of Financial Economics, Vol. 77, 2005, pp. 57-116. doi:10.1016/j.jfineco.2004.06.010
[8] F. Camara, Export and Social Networking As a Resource Control Strategy: A Case Study from Azores," Journal of Small Business and Entrepreneurship, Vol. 19, No. 4, 2006, pp. 395-408. doi: $10.1080 / 08276331.2006 .10593379$

[9] S. H. Zhang and Z. L. Chen, "SMEs' Financing Chain Based on Industrial Clusters," Business Economics and Management, 2006, Vol. 5, pp. 65-69.

[10] K. Guo, "The Transformation of China's Economic Growth Pattern-Conditions and Methods," Social Sciences in China, Vol. 18, No. 3, 1997, pp. 12-20. 